\title{
Measurement of hydrolytic activity and incorporation of dissolved organic substrates by microorganisms in marine sediments
}

\author{
Lutz-Arend Meyer-Reil \\ Institut für Meereskunde an der Universität Kiel, Abteilung Marine Mikrobiologie, Düsternbrooker Weg 20, D-2300 Kiel 1, \\ Federal Republic of Germany
}

\begin{abstract}
A core-injection technique is described which enables the assessment of microbial activities (extracellular enzymatic cleavage of carbohydrates and proteins, incorporation of dissolved organic substrates into microbial biomass) in natural sediment cores. Enzymatic activities were determined by means of fluorogenic substances (4-methylumbelliferyl- $\beta$ - $D$-glucoside, L-leucine-4methylcoumarinyl-7-amide $\mathrm{HCl}$ ); incorporation of dissolved organic substances were measured using tritiated substrates (thymidine, leucine, acetate, glucose). Microliter portions of substrates were injected at $0.5 \mathrm{~cm}$ intervals into natural sediment cores, which were incubated, quick frozen, dissected and analysed. For a proper application of the core-injection technique different parameters were investigated such as volume of substrate injected, significance of diffusion of substrate, concentration of substrate and incubation time, and treatment of samples to account for the non-biological 'turnover' of substrates. In depth profiles of sediments from the Kiel Bight (Baltic Sea; FRG), microbial extracellular enzymatic activities were highest in the surface horizons and decreased steadily with sediment depth. Incorporation rates of dissolved organic substrates, however, revealed a more complex depthdependent variation pattern indicating a pronounced stratification of microbial metabolism in the sediment cores.
\end{abstract}

\section{INTRODUCTION}

The microbiology of marine sediments has received increasing interest during recent years since coastal sediments have been recognized as important locations of nutrient regeneration in marine ecosystems. Most of the organic material entering the sediments by sedimentation is particulate organic carbon which is partly consumed directly by benthic organisms and partly incorporated into the pool of particulate carbon in the sediment. Through the activity of extracellular enzymes derived from living cells or liberated through the lysis of cells, particulate organic carbon is stepwise converted into low-molecular-weight dissolved organic carbon. By excreting extracellular enzymes and incorporating the products of the enzymatic hydrolysis, microorganisms play the key role in the decomposition processes of organic material. Through microbial activities, biomass is formed which serves as an important nutrient source for benthic organisms.

Recently, techniques have been reported for the measurement of extracellular enzymatic activities in natural waters using artificial substrates whose hydrolysis by natural occurring enzymes is followed by the liberation of highly fluorescent compounds (Hoppe 1983, Somville 1984). For the measurement of the microbial incorporation of dissolved organic substances, tritiated substrates can be applied in tracer concentrations thus changing natural substrate concentrations only minimally (King \& Klug 1982).

Sediments exhibit a high structural complexity. Activity measurements that are hoped to reflect natural conditions require the incubation of intact sediment cores. Disruption of the system (sediment dissected and suspended in seawater) leads to a considerable stimulation of microbial metabolism (Hall et al. 1972, Meyer-Reil 1978, Novitsky 1983).

In the paper presented here, a core-injection technique is described which enables the measurement of microbial activities in intact sediment cores. For a proper application of the technique, different parameters were investigated, such as volume of substrate 
injected, significance of diffusion of substrate, concentration of substrate and incubation time, and treatment of samples to account for the non-biological 'turnover' of substrate. The core-injection technique was applied to sediments from the Kiel Bight (Baltic Sea; FRG), in which depth-dependent variation of extracellular enzymatic activities and incorporation of dissolved organic substrates by microorganisms were investigated.

\section{MATERIALS AND METHODS}

Sampling. Sediment samples were collected using a Reineck grab from a muddy sand station (water depth $18 \mathrm{~m}$ ) located on the slope of the Kiel Bight channel system. The sampling area, known as 'Hausgarten', has been subject to several investigations during recent years (see Graf et al. 1983, Meyer-Reil 1983, Balzer 1984). For the aim of this paper, 3 sediment profiles will be presented which were sampled on June 19, September 20, and November 8, 1984. Surface temperatures of these sediments were 6,14 , and $11^{\circ} \mathrm{C}$, respectively. Whereas the discontinuity layer $(0 \mathrm{mV})$ of the sediments in June and September was close to the surface, the $0 \mathrm{mV}$ layer in November dropped down to $1 \mathrm{~cm}$ sediment depth.

Core-injection technique. Activity of hydrolytic enzymes and incorporation of dissolved organic substrates by microorganisms were determined in undisturbed sediment cores ( 0 to $8 \mathrm{~cm}$ depth) which were taken on board ship in plexiglas tubes $11.2 \mathrm{~cm}$ in diameter). Prior to sampling, the tubes were perforated at $0.5 \mathrm{~cm}$ intervals with $1 \mathrm{~mm}$ wide injection ports and carefully sealed with a thin layer of a one-component silicon rubber (Elchsiegel). Immediately after sampling, $10 \mu \mathrm{l}$ of the substrate tested for enzymatic hydrolysis or incorporation (see below) was injected at $0.5 \mathrm{~cm}$ intervals through the ports into the water overlying the sediment and into the sediment using a gastight syringe (Hamilton, $50 \mu \mathrm{l}$ volume). During injection the tubes were mounted on a rack which allows accurate, horizontal injection of the substrates into the centre of the sediment horizons

Activity of hydrolytic enzymes. As substrates for the measurement of the extracellular enzymatic activities (cleavage of carbohydrates and proteins), 4-methylumbelliferyl- $\beta$-D-glucoside (MUF-glu; Sigma) and Lleucine-4-methylcoumarinyl-7-amide $\mathrm{HCl}$ (MCA-leu; Serva) were used. Five $\mathrm{mM}$ solutions of the substrates were prepared in brackish water (salinity app. $10 \%$ ), filter sterilized, flushed with nitrogen, temperature equilibrated and injected in $10 \mu \mathrm{l}$ portions into the sediment horizons as described above. Sediment cores (3 parallels) were incubated at in situ temperature for
$1 \mathrm{~h}$. For the standardization experiments, injection volume, substrate concentration and incubation time were varied. After incubation the activity was terminated by freezing the sediment core in dry ice. For the analysis, the sediment cores ( 0 to $8 \mathrm{~cm}$ depth) were sectioned at $1 \mathrm{~cm}$ intervals, and the centres of the horizons cut out with a cork drill ( $4 \mathrm{~mm}$ in diameter). The material from 3 parallel sediment horizons was combined in a centrifuge tube, and $3 \mathrm{ml}$ of brackish water were added. All manipulations were carried out at $0^{\circ} \mathrm{C}$. After centrifugation $\left(15 \mathrm{~min}, 5000 \mathrm{rpm}, 0^{\circ} \mathrm{C}\right), 2.5 \mathrm{ml}$ of the supernatant was mixed in a cuvette with $0.25 \mathrm{ml}$ of buffer (sodium tetraborate/sodium hydroxide; $\mathrm{pH} \mathrm{10.8),} \mathrm{and}$ the fluorescence intensity was read in a spectrofluorometer (Jasco FP-550) at $455 \mathrm{~nm}$ under $365 \mathrm{~nm}$ excitation. A $1 \mu \mathrm{M}$ solution of methylumbelliferon was used as a standard for each measurement. Since the enzymatic hydrolyses of MUF-glu and MCA-leu, respectively, yield equimolar concentrations of the fluorescent dye and the substrate (glucose and leucine, respectively), the latter could be calculated from the amount of dye released. For each section, the dry weight of the sediment was determined; and extrapolations from dry weight to volume were made by considering the specific gravity of the individual sediment horizons.

Incorporation of dissolved organic substrates. For the measurement of the incorporation of dissolved organic carbon by microorganisms, the following substrates were used: (methyl- $\left.{ }^{3} \mathrm{H}\right)$ thymidine $\left(355 \mathrm{mCi} \mathrm{mg}^{-1}\right)$, D- $\left(2-{ }^{3} \mathrm{H}\right)$ glucose $\left(94 \mathrm{mCi}_{\mathrm{mg}}^{-1}\right), \quad \mathrm{L}-\left(4,5-{ }^{3} \mathrm{H}\right)$ leucine $\left(880 \mathrm{mCi} \mathrm{mg}^{-1}\right),\left({ }^{3} \mathrm{H}\right)$ acetate $\left(42.7 \mathrm{mCi} \mathrm{mg}^{-1}\right)$. The substrates were purchased from Amersham Buchler and diluted in particle-free brackish water to an activity of $0.25 \mu \mathrm{Ci}$ in $10 \mu \mathrm{l}$ equivalent to the following amounts: thymidine $0.70 \mathrm{ng}$ ( $3.66 \mathrm{ng})$, glucose $2.66 \mathrm{ng}$ (13.82 ng), leucine $0.28 \mathrm{ng}(1.48 \mathrm{ng})$, and acetate $5.85 \mathrm{ng}$ (30.39 ng). The values in brackets reflect the final concentration of substrates per $\mathrm{cm}^{3}$ of sediment. For this calculation, the volume of the sediment segment analysed was extrapolated to $1 \mathrm{~cm}^{3}$. After injection of $10 \mu \mathrm{l}$ portions of substrate into the sediment horizons (3 parallels), samples were incubated at in situ temperature for $3 \mathrm{~h}$, and fixed in dry ice. For the analysis the sediment cores were sectioned at $1 \mathrm{~cm}$ intervals $(0$ to $8 \mathrm{~cm}$ depth), the centres of the horizons cut out with a cork drill ( $7 \mathrm{~mm}$ in diameter), the material from 3 parallel horizons combined in a centrifuge tube, and $3 \mathrm{ml}$ of brackish water added. The sediment was washed at least 3 times with brackish water by centrifugation (15 min; $5000 \mathrm{rpm}$ ) until the radioactivity in the supernatant was removed. All manipulations were carried out at $0^{\circ} \mathrm{C}$. After drying the weight of the sediment was determined, an equal volume of cellulose powder was added, and tablets were pressed 
which were then oxidized in a Tri-Carb Oxidizer (Packard), and analysed with $15 \mathrm{ml}$ of Monophase 40 in a liquid scintillation counter (Betazint 5000).

Controls for the assessment of the non-biological 'activities' (enzymatic hydrolysis, incorporation of dissolved organic substrates) were run with mixed sediment from the individual horizons which were sterilized by autoclaving $\left(30 \mathrm{~min}, 121^{\circ} \mathrm{C}\right)$. In parallel, other fixation treatments were examined (see below).

\section{RESULTS AND DISCUSSION}

\section{Core-injection technique}

The core-injection technique described enables the measurement of microbial activities (enzymatic hydrolysis, incorporation of dissolved organic substrates) in sediment cores under conditions close to those in situ. Since the sediments remain intact, natural gradients and diffusion processes are only minimally altered. Similar techniques have been successfully applied by Jørgensen (1978) and Ansbaek \& Blackburn (1980).

For the proper application of the core-injection technique, different parameters were examined: volume of substrate injected, significance of diffusion of substrate within the sediment volume analysed, concentration of substrate injected and incubation time, activity in 'parallel' sediment cores, treatment of sediments to account for the non-biological 'turnover' of substrates (controls), activity in undisturbed versus disturbed sediments. Most of the standardization experiments were carried out using 4 -methylumbelliferyl- $\beta$ D-glucoside (MUF-glu) as substrate.

\section{Injection volume}

In natural sediment cores, 2, 5, 10 and $15 \mu \mathrm{l}$ of MUFglu $(5 \mathrm{mM}$ solutions) were injected, and enzymatic hydrolysis rates were determined. Up to $10 \mu \mathrm{l}$, the activities increased linearly. With $15 \mu$ linjected, there was no significant increase in the hydrolysis rates. Similar results were obtained for the incorporation of $\left({ }^{3} \mathrm{H}\right)$ glucose. For subsequent field studies, a volume of $10 \mu \mathrm{l}$ of substrate was chosen. The choice of this volume represented a compromise. On the one hand, substrate limitation should be avoided in the sediment horizons, and on the other hand, dilution of the pore water by the volume of substrate injected should be kept low. Considering a water content of $35 \%$ (typical for the 0 to $1 \mathrm{~cm}$ horizon of the sediments investigated), the volume of substrate injected led to a dilution of the pore water by $15 \%$; based on a water content of $25 \%$ (typical for deeper sediment horizons), however, the dilution was $21 \%$. The calculation of these values was based on the assumption that the substrate injected was initially homogeneously distributed through the sediment segments analysed. In reality, however, the dilution rates changed with time.

\section{Substrate transport}

Through the injection of substrate, a concentration gradient was created within the sediment. Initially, the substrate was concentrated in the centre at each depth. During incubation, the substrate spread out due to active and passive transport. Two sets of experiments were carried out to assess the significance of diffusion on the activity measurements. By using cork drills of different diameters, the enzymatic hydrolysis of MUFglu was analysed at different distances from the centre. It could be demonstrated that even in the peripheral part of the sediment segments analysed, $80 \%$ of the activity of the centre could still be measured. Similar results were obtained in experiments in which MUFglu was injected in every second horizon of the sediment core. On average, sediment horizons that were initially not supplied with substrate revealed a reduction in activity by $10 \%$ as compared to the horizons that received the substrate. Parallel sediment cores in which every horizon was supplied with substrate on average showed a $20 \%$ higher activity. This can be explained by the fact that both the substrate (MUF-glu) and the product of the enzymatic reaction (MUF) were subject to transport in the pore water. This led to a 'loss' of activity in the injected horizons of those sediment cores in which only every second horizon was supplied with substrate. Corresponding experiments with tritiated substrates were not carried out. However, the solubility of the substrates used and the incubation time of $3 \mathrm{~h}$ (see 'Materials and Methods') imply sufficient transport within the sediment volume analysed.

\section{Concentration of substrate and incubation time}

The proper measurement of activity rates requires: (a) linearity of activity over time (absence of substrate exhaustion or induction), and (b) minimal changes of substrate concentrations during incubation (Harrison et al. 1971). To confirm these requirements, a range of substrate concentrations was applied whose turnover was measured in time-course experiments. To reduce the heterogeneity of natural sediments, the plexiglas tubes were supplied with mixed sediment that was allowed to sit for $12 \mathrm{~h}$ prior to injection of substrate. Concentrations of $1,2.5$, and $5 \mathrm{mM} \mathrm{MUF-glu} \mathrm{and}$ MCA-leu, respectively, revealed linear hydrolysis 
curves over an incubation time of at least $2 \mathrm{~h}$. How ever, even the highest concentration $(5 \mathrm{mM})$ did not saturate the enzymes. Since MUF-glu as well as MUFleu are soluble in brackish water only up to a concentration of $5 \mathrm{mM}$, this concentration in connection with an incubation time of $1 \mathrm{~h}$ was applied in subsequent field studies. Experiments with tritiated substrates using different concentrations and incubation times were not always satisfactory. Parallel measurements differed considerably which may be explained by small-scale differences in the activity of 'parallel' cores. With relatively low activities of ${ }^{3} \mathrm{H}$-glucose $10.025,0.05,0.1 \mu \mathrm{Ci}$, equivalent to $0.27,0.53$, and $1.06 \mathrm{ng}$ per $10 \mu \mathrm{l}$ injected), a rapid exhaustion of substrate was observed. Higher activities $10.25,0.5 \mu \mathrm{Ci}_{\text {, }}$ equivalent to 2.66 and $5.32 \mathrm{ng}$, respectively, per $10 \mu$ injected), allowed a linear increase of incorporation rates for at least $5 \mathrm{~h}$. Corresponding straight lines were obtained for the microbial incorporation of ${ }^{3} \mathrm{H}$-acetate (K. Lochte pers. comm.). Subsequent field studies were based on an activity of $0.25 \mu \mathrm{Ci}$ (per $10 \mu \mathrm{l}$ of substrate injected) which guaranteed a linear activity over time without changing the natural concentration to a great extent (see below)

\section{Activity in parallel sediment cores}

Due to the heterogeneity of natural samples, enzymatic hydrolysis and incorporation of dissolved organic substrates measured in sediment cores taken from one grab could vary by a factor of up to 3 . The variation of 'parallel' cores was highest in the top $\mathrm{cm}$ and decreased with sediment depth. 'Conservative' parameters such as thymidine incorporation revealed significantly less variations as compared to incorporation rates of glucose, acetate or leucine. However, if the sediment was thoroughly mixed and subsamples were taken immediately after mixing, the variations in activities were greatly reduced. Experimental error itself was generally less than $10 \%$ (standard deviation of the mean value). The analysis of the sediment cores as outlined in 'Materials and Methods' represented a compromise: 3 parallel cores per substrate were incubated; for the analysis, however, the material from the 3 parallel horizons was combined.

\section{Controls}

Introductory experiments for the assessment of the non-biological 'turnover' of substrates were carried out with natural sediment cores that were autoclaved or in which formalin was injected prior to the injection of substrate. Both treatments turned out to be not very promising. Autoclaving caused a disruption of the sediment cores. Enzymatic hydrolysis and incorporation rates of dissolved organic substrates in formalin treated cores were disproportionately high (up to $50 \%$ of the activity in untreated cores) even after formalin was injected prior to the injection of substrate. For subsequent field studies, mixed sediment obtained from dissecting sediment cores according to the corresponding horizons served as controls. Control samples varied significantly dependent on the sample, the substrate and the kind of fixation. Generally, autoclaved sediments showed the lowest control values. Samples fixed with concentrated formalin or glutaraldehyde were higher by a factor of 2 to 4 . From the dissolved organic substrates, the lowest controls were observed with glucose or thymidine as substrates; considerably higher controls were found with charged substrates such as acetate or leucine.

The treatment of sediment samples to account for the non-biological 'turnover' of substrates (controls) is only poorly addressed in the literature. Each kind of fixation (heating, chemical treatments) causes alterations in the structure and the adsorption properties of the sediment, so that 'absolute' control values are difficult to obtain. The problem of proper controls arises especially in those sediment horizons where low microbial activities may be altered considerably by questionable controls.

Activity in undisturbed versus disturbed sediments

Exoenzymatic hydrolysis and incorporation of dissolved organic substrates in sediment cores that were dissected and suspended in brackish water were on average 1 order of magnitude higher as compared to undisturbed sediments. The relative increase in activity in disturbed sediments varied with substrate and sediment depth. Corresponding observations have been reported by other authors (Hall et al. 1972, Meyer-Reil 1978, Novitsky 1983). In seeking an explanation, the complex structure of sediments and the bacterial colonization of particles have to be considered. Through the disruption of the sediment fine structure, microenvironments are destroyed, bacterial aggregates are split up, and cells or groups of cells are separated from each other. The cells are optimally supplied with substrate; phenomena such as competition or inhibition of substrate uptake are diminished. Based on the increase of microbial activities in disturbed samples, sediments have to be characterized as biotopes of a considerable potential activity; and one may image the importance of natural mixing processes such as bioturbation or mechanical disturbance by waves for the stimulation of microbial activities. 


\section{Microbial activities in natural sediments}

Based on the core-injection technique described, hydrolytic activities and incorporation rates of dissolved organic substrates by microorganisms were followed in sediment profiles sampled on June 19, September 20, and November 8, 1984, from a muddy sand station of the Kiel Bight. The activity of hydrolytic enzymes was measured using 4-methylumbelliferyl- $\beta$ D-glucoside (MUF-glu) and L-leucine-4-methylcoumarinyl-7-amide $\mathrm{HCl}$ (MCA-leu) as substrates (for literature see Hoppe 1983, Somville 1984). This fluorimetric assay is much more sensitive than the photometric determination based on covalent-bound dye derivates (amylopectin azure, hide powder azure) used in former sediment investigations (Meyer-Reil 1983). To my knowledge, this is the first time that the fluorimetric assay was applied to sediments. MUF-glu and MCA-leu represent model substrates which are analogs for a variety of natural occurring substrates of unknown concentration and composition. Because of this, the microbial hydrolysis rates measured describe potential activities. However, the rates measured reflect the pool of natural occurring enzymes which is the result of variations in concentration and composition of natural substrates.

For the measurement of the microbial incorporation of dissolved organic substances, glucose, leucine, and acetate were chosen which partly represent products of the hydrolytic activities and partly intermediary products of the anaerobic microbial metabolism. Parallel determinations of the incorporation of thymidine were used as a relative indicator for microbial growth (without any intention to calculate growth rates; see Pollard \& Moriarty 1984).

The activity rates measured characterize the incorporation of dissolved organic substrates into microbial biomass. Respiration as well as excretion of substances could not be considered. From the analysis it could not finally be distinguished between the incorporation of the added substrate and (or) its metabolic products excreted during cell metabolism into the pore water. This applies especially to the anaerobic decomposition of glucose which yields low molecular weight fatty acids, mainly acetate (King \& Klug 1982). Through the application of the tritiated substances, tracer amounts could be injected into the sediment horizons. However, the natural concentrations of the substrates are unknown. Based on the very few reliable data available for the natural concentrations of glucose (MeyerReil et al. 1980, King \& Klug 1982) and acetate (Ansbaek \& Blackburn 1980, Christensen \& Blackburn 1982 ) in sediments, it can be derived that the concentrations added amounted to less than $10 \%$ of the natural concentrations. This means that the incorpora-

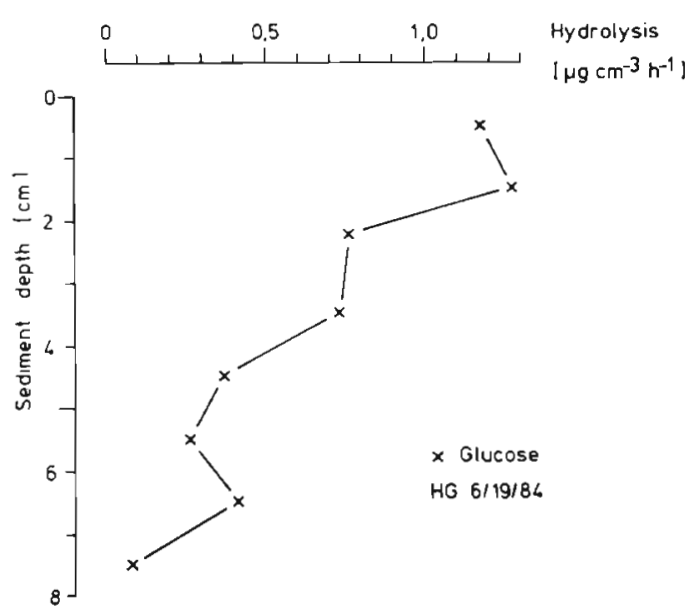

Fig. 1. Hydrolysis of 4-methylumbelliferyl- $\beta$-D-glucoside $(\mu \mathrm{g}$ glucose released). Sediment profile from Kiel Bight, Station 'Hausgarten' (HG), 19 Jun 1984

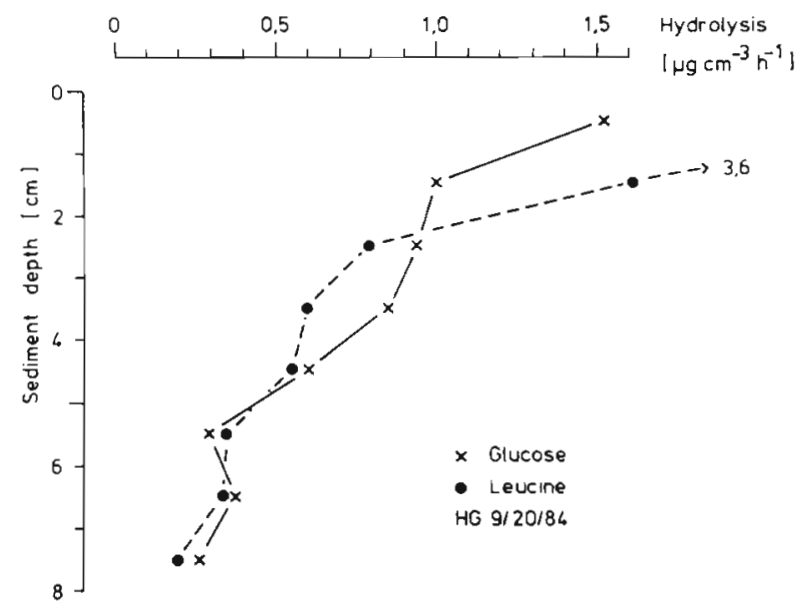

Fig. 2. Hydrolysis of 4-methylumbelliferyl- $\beta$-D-glucoside and L-leucine-4-methylcoumarinyl-7-amide $\mathrm{HCl}(\mu \mathrm{g}$ glucose and leucine, respectively, released). Sediment profile from Kiel Bight, 20 Sep 1984

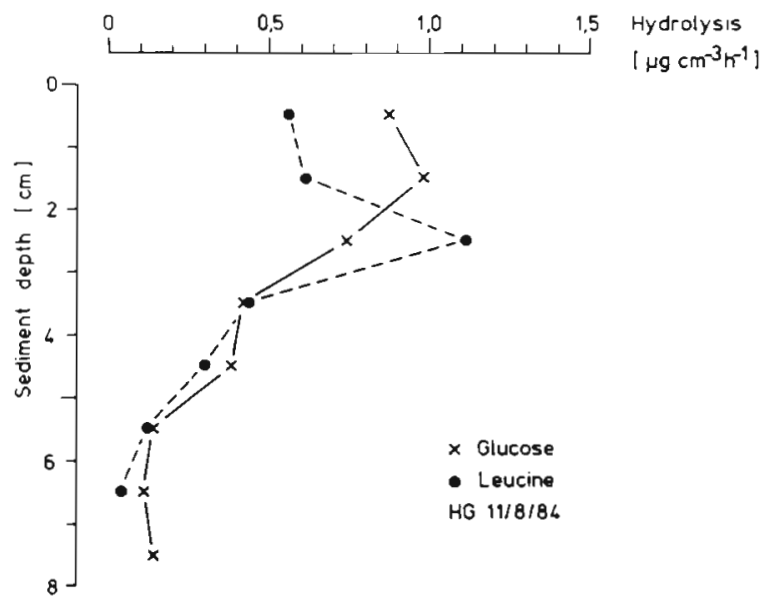

Fig. 3. Hydrolysis of 4-methylumbelliferyl- $\beta$-D-glucoside and L-leucine-4-methylcoumarinyl-7-amide $\mathrm{HCl}(\mu \mathrm{g}$ glucose and leucine, respectively, released). Sediment profile from Kiel Bight, 8 Nov 1984 
tion rates reported have to be multiplied at least by a factor of 10 in order to derive actual incorporation rates. However, even if natural concentrations are known, the question arises what percentage of the substrate is available for microbial metabolism (Christensen \& Blackburn 1982, Thompson \& Nedwell 1985).

In sediments of the Kiel Bight, extracellular enzymatic activities were generally highest in the surface layer $(0$ to $2 \mathrm{~cm})$ and decreased steadily with depth (Fig. 1 to 3). The hydrolysis of MUF-glu and MCA-leu could differ considerably at the surface, but converged with depth. In the 7 to $8 \mathrm{~cm}$ horizon less than $15 \%$ of the activity at the surface was measured. These observations indicate that the enzymatic decomposable material accumulated mainly at the sediment surface, obviously due to the sedimentation of organic material from the water column (see Graf et al. 1983, MeyerReil 1983). Although the total organic matter content (determined as ignition lost) often increased in medium sediment horizons ( 4 to $5 \mathrm{~cm}$; data not shown), this increase was not reflected by a corresponding stimulation of extracellular enzymatic activities. Since this material obviously withstands an easy microbial hydrolytic attack, it has to be characterized as more resistant. The fate of this material is uncertain. Part of it may be burried in deeper sediment horizons (Balzer 1984); part of it may be slowly decomposed. As could be shown by Shimp \& Pfaender (1985), the microbial decomposition of the more resistant organic material will be considerably stimulated by the availability of easily decomposable organic substances.

Incorporation rates of dissolved organic substrates in sediments of the Kiel Bight revealed a complex variation pattern which differs from the conventional picture of steadily decreasing microbial parameters with increasing sediment depth (Fig. 4 to 6). Generally, the highest incorporation rates were measured at the surface. An exception was the sediment profile of June 19 in which the highest incorporation rates of thymidine and acetate were determined in deeper sediment horizons ( 1 to $2 \mathrm{~cm}$ and 2 to $3 \mathrm{~cm}$, respectively; see Fig. 4). Although the incorporation rates generally decreased with sediment depth, steadily decreasing activities were the exception. Dependent on the sample and the substrate, zonations in the activity were observed which indicate a stratification of microbial metabolism in the sediment profiles.

A comparison of the incorporation rates of dissolved organic substrates into microbial biomass measured at the 3 different periods (cf. Fig. 4 to 6 ) indicates an obvious seasonal influence: activities were highest in late summer. Generally, lower activities were recorded in fall, and the lowest activities were measured in late spring.

The incorporation rates of leucine and thymidine

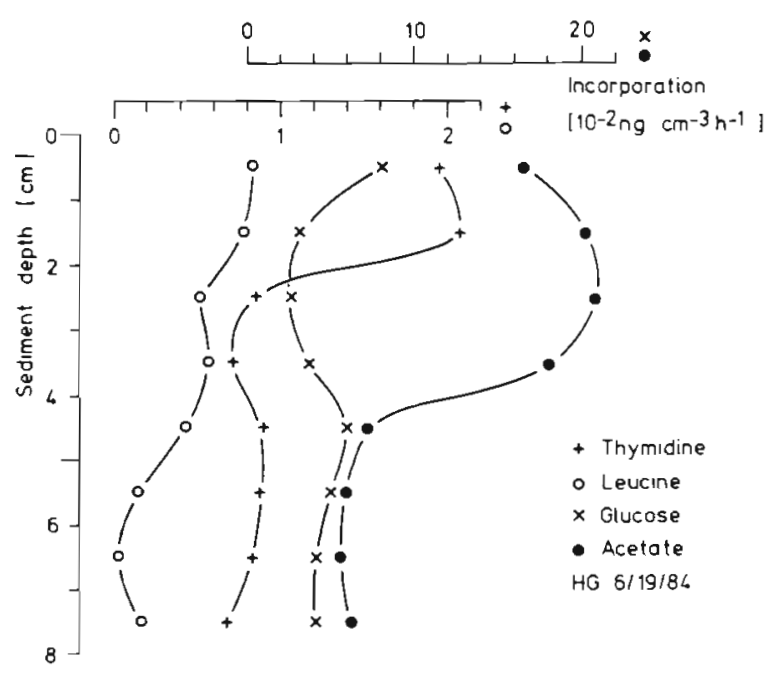

Fig. 4. Incorporation of ${ }^{3} \mathrm{H}$-thymidine, leucine, glucose, and acetate. Sediment profile from Kiel Bight, 19 Jun 1984

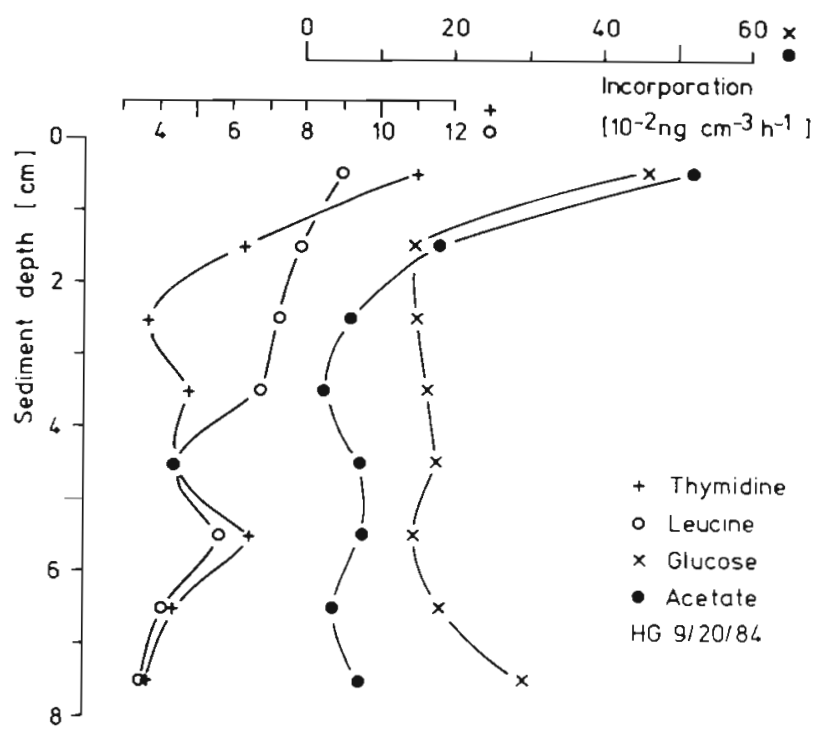

Fig. 5. Incorporation of ${ }^{3} \mathrm{H}$-thymidine, leucine, glucose, and acetate. Sediment profile from Kiel Bight, 20 Sep 1984

revealed a similar depth-dependent variation pattern: activities differed at the surface but converged with sediment depth. If leucine incorporation represents protein synthesis (Kirchman et al. 1985) and thymidine incorporation represents DNA-synthesis (Pollard \& Moriarty 1984), both activities should by synchronized at least during balanced growth.

From the sediment profile of June 19 (Fig. 4), it became especially obvious that the incorporation rates of glucose and acetate varied oppositely. In the 0 to $2.5 \mathrm{~cm}$ horizon, acetate incorporation increased with decreasing glucose incorporation. In the 2.5 to $4.5 \mathrm{~cm}$ horizon, however, acetate incorporation decreased whereas the incorporation of glucose increased. Below 


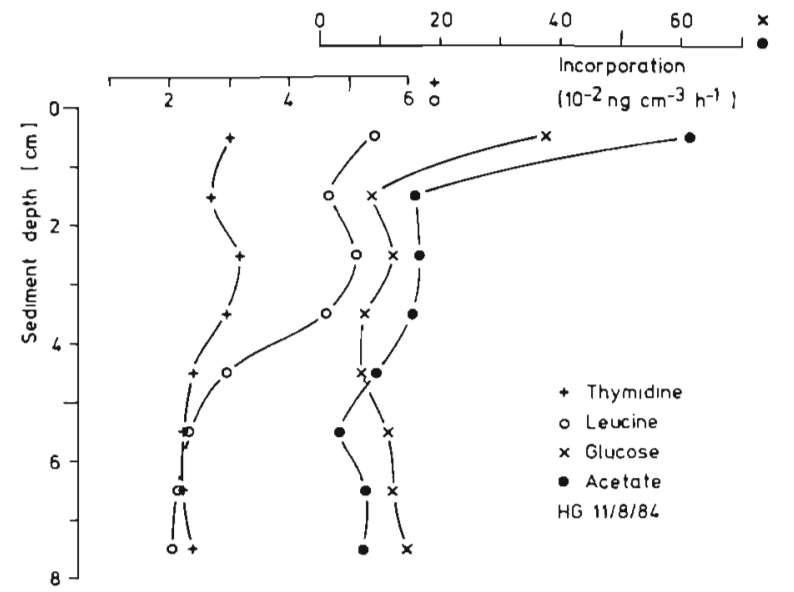

Fig. 6. Incorporation of ${ }^{3} \mathrm{H}$-thymidine, leucine, glucose, and acetate. Sediment profile from Kiel Bight, 8 Nov 1984

a sediment depth of $5 \mathrm{~cm}$, both activities showed parallel curves. From the other sediment samples, only the profile of November 8 may give some indication for an inverse relation between the incorporation of glucose and acetate (see Fig. 5 \& 6).

Because of the reasons stated above, the microbial incorporation of glucose is difficult to interpret, especially in anaerobic sediments. The incorporation of acetate, however, revealed a pronounced relation to the cycle of sulfate: maxima in sulfate reduction coincided with maxima in the acetate incorporation (Pollehne \& Meyer-Reil unpubl. data). These observations underline the importance of acetate as a substrate for sulfate reducers in the sediments investigated.

A study is in progress to relate seasonal variations in hydrolytic activities and microbial incorporation of dissolved organic substrates to the input of organic material into sediments of the Kiel Bight. From this study further insights into the regulation of benthic microbial metabolism can be expected.

Acknowledgements. I thank E. Boß and W. Plänitz for valuable assistance. U. Rabsch and P. Krischker kindly supported our work in the isotope laboratory. This work was supported by the German Research Council (Deutsche Forschungsgemeinschaft) grant Me 509/3-1.

\section{LITERATURE CITED}

Ansbaek, J., Blackburn, T. H. (1980). A method for the analysis of acetate turnover in a coastal marine sediment. Microb. Ecol. 5: 253-264

Balzer, W. (1984). Organic matter degradation and biogenic element cycling in a nearshore sediment (Kiel Bight). Limnol. Oceanogr. 29: 1231-1246

Christensen, D., Blackburn, T. H. (1982). Turnover of ${ }^{14} \mathrm{C}$ labelled acetate in marine sediments. Mar. Biol. 71: $113-119$

Graf, G., Schulz, R., Peinert, R., Meyer-Reil, L.-A. (1983). Benthic response to sedimentation events during autumn to spring at a shallow water station in the Western Kiel Bight. I. Analysis on a community level. Mar. Biol. 77: 235-246

Hall, K. J., Kleiber, P. M., Yesaki, I. (1972). Heterotrophic uptake of organic solutes by microorganisms in the sediment. Mem. Ist. Ital. Idrobiol., 29 Suppl.: 441-471

Harrison, M. J., Wright, R. T., Morita, R. Y. (1971). Method for measuring mineralization in lake sediments. Appl. environ. Microbiol. 21: 698-702

Hoppe, H.-G. (1983). Significance of exoenzymatic activities in the ecology of brackish waters: measurements by means of methylumbelliferyl-substrates. Mar. Ecol. Prog. Ser. 11: 299-308

Jørgensen, B. B. (1978). A comparison of methods for the quantification of bacterial sulfate reduction in coastal marine sediments. I. Measurement with radiotracer techniques. Geomicrobiol. J. 1: 11-27

King, G. M., Klug, M. J. (1982). Glucose metabolism in sediments of a eutrophic lake: tracer analysis of uptake and product formation. Appl. environ. Microbiol. 44: 1308-1317

Kirchman, D., K'nees, E., Hodson, R. (1985). Leucine incorporation and its potential as a measure of protein synthesis by bacteria in natural aquatic systems. Appl. environ. Microbiol. 49: 599-607

Meyer-Reil, L.-A. (1978). Uptake of glucose by bacteria in the sediment. Mar. Biol. 44: 293-298

Meyer-Reil, L.-A. (1983). Benthic response to sedimentation events during autumn to spring at a shallow water station in the Western Kiel Bight. II. Analysis of benthic bacterial populations. Mar. Biol. 77: 247-256

Meyer-Reil, L.-A., Bölter, M., Dawson, R., Liebezeit, G., Szwerinski, H., Wolter, K. (1980). Interrelationships between microbiological and chemical parameters of sandy beach sediments, a summer aspect. Appl. environ. Microbiol. 39: 797-802

Novitsky, J. A. (1983). Microbial activity at the sedimentwater interface in Halifax Harbor, Canada. Appl. environ. Microbiol. 45: 1761-1766

Pollard, P. C., Moriarty, D. J. W. (1984). Validity of the tritiated thymidine method for estimating bacterial growth rates: measurement of isotope dilution during DNA synthesis. Appl. environ. Microbiol. 48: 1076-1083

Shimp, R. J., Pfaender, F. K. (1985). Influence of easily degradable naturally occurring carbon substrates on biodegradation of monosubstituted phenols by aquatic bacteria. Appl. environ. Microbiol. 49: 394-401

Somville, M. (1984). Measurement and study of substrate specifity of exoglucosidase activity in eutrophic water. Appl. environ. Microbiol. 48: 1181-1185

Thompson, L. A., Nedwell, D. B. (1985). Existence of different pools of fatty acids in anaerobic model ecosystems and their availability to microbial metabolism. FEMS Microbiol. Ecol. 31: 141-146 